\title{
Association of Blood Groups with the Extent and Severity of Coronary Lesions in Patients with Acute Myocardial Infarction
}

Jehangir Ali Shah', Gulzar Ali', Rajesh Kumar', Kamran Ahmed Khan', Abdul Hakeem', Danish Qayyum' Mehwish Zehra', Farah Naz', Jawaid Akbar Sial', Tahir Saghir', Musa Karim'

National Institute of Cardiovascular Diseases (NICVD), Karachi, 2Jinnah Post Graduate Medical Center (JPMC), Karachi, Pakistan.

\begin{abstract}
Background: Coronary Artery Disease (CAD) is a complex interaction of genetic and multifactorial environmental factors. This study was conducted to evaluate the association of blood groups with the severity of coronary artery lesions in patients with acute myocardial infarction undergoing primary percutaneous coronary intervention (PCI).

Methods: This descriptive cross-sectional study was conducted at a tertiary cardiac care center in Karachi, Pakistan. Consecutive adult patients of either gender diagnosed with ST-segment elevation myocardial infarction (STEMI) undergone primary PCl during the study period of November 2020 to February 2021 were included. Based on blood grouping patients were stratified into two groups, non-O and $O$. comparative analysis of clinical and angiographic findings was performed and Chi-square test was used with $p$-value $\leq 0.05$ was considered statistically significant.
\end{abstract}

Results: A total of 398 patients were included in this study out of which $296(74.4 \%)$ were males (mean age: $57.15 \pm 10.95$ years) and $102(25.6 \%)$ females. Type $O$ blood group distribution was $107(26.9 \%)$ and non-O blood groups were $291(73.1 \%)$. The non-O blood group included $A=110(27.6 \%), A B=43(10.8 \%)$, and $B=138(34.7 \%)$. Significant results in type $O$ and non-O group were seen among single vessel diseases $(41.1 \%, 29.6 \%)(p=0.029)$ and circumflex artery as culprit $(16.8 \%, 9.6 \%)(p=0.046)$, whereas in post-procedure complication no significant results were found $(p=0.554)$ with in-hospital mortality rate $(p=0.642)$.

Conclusion: Blood group type O was found to be associated with single-vessel coronary artery diseases. However, no association of blood groups was observed with lesion complexity, post-procedure complications and mortality.

Keywords: Ischemic Heart Diseases; Coronary Artery Diseases; Myocardial Infarction; Blood Group.

\section{Corresponding Author:}

Dr. Jehangir Ali Shah

Department of Adult Cardiology,

National Institute of Cardiovascular Diseases (NICVD),

Karachi, Pakistan.

Email: dr_shah_80@hotmail.com

https://doi.org/10.36283/PJMD11-1/004

How to cite: Shah JA, Ali G, Kumar R, Khan KA, Hakeem A, Qayyum D, et al. Association of Blood Groups with the Extent and Severity of Coronary Lesions in Patients with Acute Myocardial Infarction. 2022;11 (1): 17-24. doi: 10.36283/PJMD11-1/004 


\section{INTRODUCTION}

The Asian population, especially South Asians, remains at an increased risk of ischemic heart diseases (IHD), contrary to the western world, an increase in the prevalence of coronary artery diseases (CAD) is expected for this region in the next few decades'. Increased efforts in the last decades towards primary prevention, evidence-based medicines, treatments, and diagnosis have resulted in a dramatic decline in mortalities and morbidities due to IHD in Western countries ${ }^{2}$. However, increasing trends in low and middle-income countries (LMCS) pose new challenges for global public health, collectively. LMCs contribute to $80 \%$ of global deaths due to cardiovascular diseases $(C V D)^{2,3}$. Drastic preventive and curative measures with a deeper understanding of underlying indigenous causative factors are crucial to tackling the impending epidemic of CAD in these regions ${ }^{4,5}$.

Worsening of metabolic risk factors is among the leading factors associated with CAD, these include high body fat (cholesterol), obesity (high body mass index), hypertension, and diabetes. Tobacco consumption, mainly in the form of smoking, has also been the leading risk factor for years of life lost due to $\mathrm{CAD}^{6}$. Previously, mass media campaigns to promote a healthy lifestyle along with preventive measures such as increased taxation on tobacco products, restrictions on smoking in public places, health warnings on the packaging of cigarettes, and free blood pressure screening events in major cities have proved effective in decreasing disease burden in high-income countries ${ }^{7}$. However, the increasing trend of CAD in low- and middle-income countries can be partly associated with the increasing urbanization and adoption of westernized lifestyles without proper access to such programs ${ }^{8}$.

Pathogenesis of CAD is a complex interaction of genetic and multifactorial environmental factors? In addition to the traditional risk factors, blood group antigens are thought to have an association with CAD but the mechanism behind this association is not very clear ${ }^{10,11}$. Ethnic differences in $A B O$ blood type locus have been reported which can be a major determinant of differences in CAD risk among various ethnicities, however, evidence is inconsistent for linking of $\mathrm{ABO}$ groups to coronary atherosclerosis $^{12}$. Some studies have reported an association between increased risk of CAD and ABO group, ${ }^{13,14}$ while other studies have shown no evidence of reported association ${ }^{15,16}$. Local evidence is lacking regarding the association of $A B O$ distribution with the extent and severity of $C A D$, especially in the context of acute myocardial infarction (AMI), in the Pakistani population. Therefore, this study was conducted to evaluate the non- $\mathrm{O}$ and $\mathrm{O}$ blood group distribution and its association with the extent and severity of coronary artery lesions in AMI patients with acute myocardial infarction undergoing primary percutaneous coronary intervention (PCI) at a tertiary care cardiac hospital in Karachi, Pakistan.

\section{METHODS}

This descriptive cross-sectional study was conducted at a tertiary care public sector cardiac center of Karachi, Pakistan. This study was approved by the ethical review committee of the National Institute of Cardiovascular Diseases (NICVD), Karachi (ER-45/2020). The consent for participation and publication was obtained from all the patients included in the study. Inclusion criteria for the study were consecutive adult patients of either gender diagnosed with ST-segment elevation myocardial infarction (STEMI) undergone primary $\mathrm{PCl}$ during the study period of four months from November 2020 to February 2021. Exclusion criteria for the study were patients with a history of cardiac intervention or surgery for any valvular, congenital, or ischemic heart diseases, patients with dilated cardiomyopathy, thyroid diseases, or chronic kidney disease as such patients were expected to have more severe coronary lesions.

Data for this study were collected on a structured proforma consisting of demographic characteristics (gender, age, weight, and height), co-morbid conditions (diabetes, hypertension, positive family history for coronary artery diseases (CAD), obesity, and smoking), presentation details (Killip class, time of presentation, and vital signs at presentation), angiographic findings (coronary dominance, number of diseased vessels, localization of diseases (culprit artery), stenosis (\%), lesion length, lesion complexity (Syntax score II), pre and post-procedure thrombolysis in myocardial infarction (TIMI) flow grade, and procedural details), and post-procedure complications and in-hospital outcomes (requirement of mechanical ventilation, arrhythmias/heart block, cardiogenic shock, acute kidney injury (AKI), slow/no-reflow, bleeding (gastrointestinal/ access site), sepsis, acute stent thrombosis, cardiac arrest, pulmonary edema, or in-hospital mortality).

$A B O$ and $R h(D)$ blood grouping of the patients were determined by the conventional blood grouping test using the tile and tube method as well as anti-AB Immonet $\mathrm{Kit}$ in the hospital pathology laboratory. All primary $\mathrm{PCl}$ procedures were performed by experienced interventional cardiologists using a femoral or radial approach. Pre-treatment with anti-platelet drugs according to standard guidelines were initiated includes a 600 mg loading dose of clopidogrel plus $325 \mathrm{mg}$ aspirin before the procedure and 70-100 IU/kg intravenous unfractionated heparin during the procedure. 
Analysis of collected data was performed by using IBM SPSS version 21. Based on blood grouping patients were stratified into two groups, non-O and $O$, and comparative analyses were performed. Continuous variables such as age, weight, height, body mass index (BMI), symptom to hospital arrival time, door to balloon time, total ischemic time, systolic blood pressure, diastolic blood pressure, heart rate, stenosis (\%), LVEF (\%), and length of the lesion were summarized with mean \pm standard deviation (SD) or median [interquartile range (IQR)]. The blood group was compared for the continuous variables by applying an independent sample t-test. Frequency and percentages were computed for categorical variables and their association with non- $O$ and $O$ groups were assessed by applying the Chi-square test. The p-value of $\leq 0.05$ was taken statistically significant.

\section{RESULTS}

A total of 398 patients were included in this study out of which $74.4 \%$ (296) were male patients and the mean age of the study sample was $57.15 \pm 10.95$ years with $28.1 \%$ (112) of the patients aged above 64 years of age. Blood group distribution was $26.9 \%$ (107) blood group type $O$. While remaining $73.1 \%$ (291) with non-O blood groups consisted of $27.6 \%$ (110) type $A, 10.8 \%$ (43) type $A B$, and $34.7 \%$ (138) type $B$ (Figure 1). Demographic and clinical characteristics of the patients stratified by the blood group type are presented in Table 1. Comparative analysis of the patients in blood group type $O$ and non-O showed no statistically significant differences in demographic distribution, the prevalence of co-morbid conditions, type of myocardial infarction, and clinical presentation.

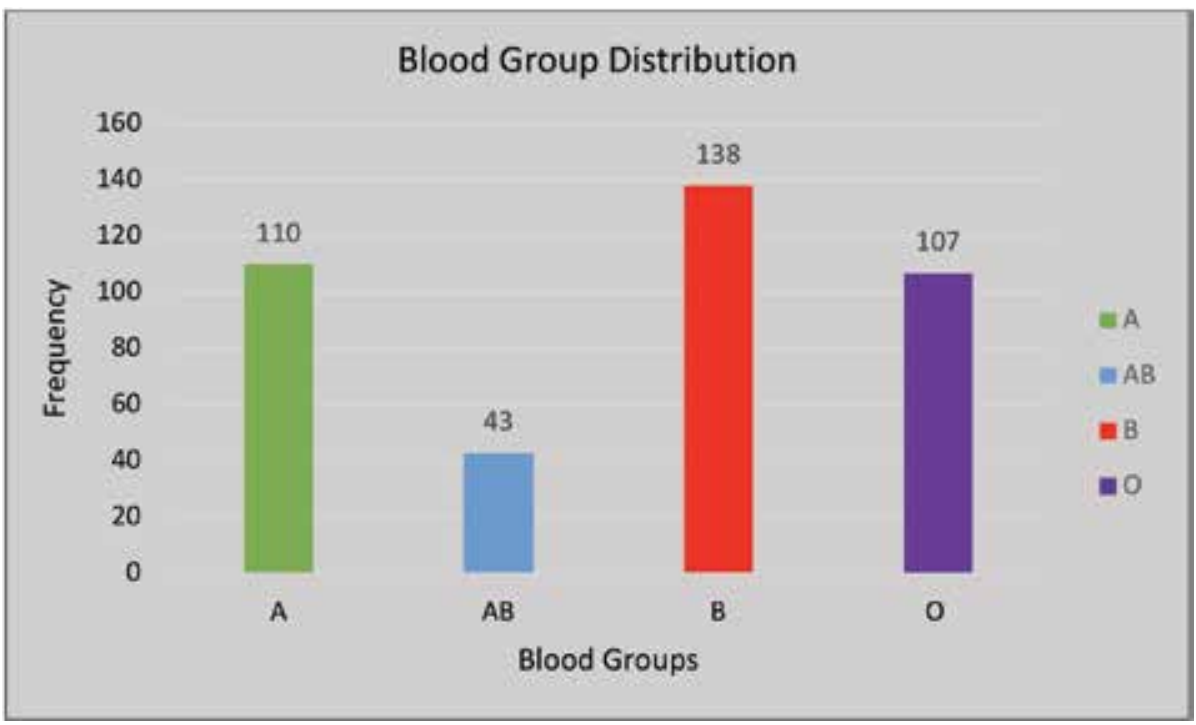

Figure 1: Blood groups distribution of the participants.

Table 1: Demographic and clinical characteristics of the patients stratified by the blood group type.

\begin{tabular}{|c|c|c|c|c|}
\hline \multirow{3}{*}{$\begin{array}{l}\text { Parameters } \\
N=398\end{array}$} & \multirow{3}{*}{$\begin{array}{c}\text { Frequency } \\
\text { (n) (\%) /Mean } \pm \text { SD/ } \\
\text { Interquartile Range }\end{array}$} & \multicolumn{2}{|c|}{ Blood Group } & \multirow{3}{*}{$\frac{p \text {-Value }}{-}$} \\
\hline & & Non-O & 0 & \\
\hline & & 291 (73.1\%) & 107 (26.9\%) & \\
\hline \multicolumn{5}{|c|}{ Baseline demographic } \\
\hline Males & $296(74.4 \%)$ & $212(72.9 \%)$ & $84(78.5 \%)$ & \multirow{2}{*}{0.252} \\
\hline Female & $102(25.6 \%)$ & $79(27.1)$ & $23(21.5 \%)$ & \\
\hline Mean age (years) & $57.15 \pm 10.95$ & $56.82 \pm 10.59$ & $58.07 \pm 11.88$ & 0.314 \\
\hline Elderly ( $\geq 65$ years) & $112(28.1 \%)$ & $78(26.8 \%)$ & $34(31.8 \%)$ & 0.328 \\
\hline Weight (kg) & $71.16 \pm 7.62$ & $70.73 \pm 7.66$ & $72.31 \pm 7.4$ & 0.067 \\
\hline Height $(\mathrm{cm})$ & $169.97 \pm 4.31$ & $169.81 \pm 4.42$ & $170.4 \pm 3.98$ & 0.226 \\
\hline $\mathrm{BMI}\left(\mathrm{kg} / \mathrm{m}^{2}\right)$ & $24.63 \pm 2.57$ & $24.53 \pm 2.56$ & $24.91 \pm 2.58$ & 0.186 \\
\hline
\end{tabular}




\begin{tabular}{|c|c|c|c|c|}
\hline \multicolumn{5}{|c|}{ Type of myocardial infarction } \\
\hline Anterior & $227(57 \%)$ & $163(56 \%)$ & $64(59.8 \%)$ & 0.497 \\
\hline Inferior & $119(29.9 \%)$ & $89(30.6 \%)$ & $30(28 \%)$ & 0.623 \\
\hline Inferior with RV & $31(7.8 \%)$ & $26(8.9 \%)$ & $5(4.7 \%)$ & 0.160 \\
\hline Lateral & $11(2.8 \%)$ & $8(2.7 \%)$ & $3(2.8 \%)$ & 0.976 \\
\hline Posterior & $10(2.5 \%)$ & $5(1.7 \%)$ & $5(4.7 \%)$ & 0.095 \\
\hline \multicolumn{5}{|c|}{ Co-morbid conditions } \\
\hline Diabetes & $167(42 \%)$ & $124(42.6 \%)$ & $43(40.2 \%)$ & 0.664 \\
\hline Hypertension & $214(53.8 \%)$ & $161(55.3 \%)$ & $53(49.5 \%)$ & 0.304 \\
\hline Obesity & $50(12.6 \%)$ & $37(12.7 \%)$ & $13(12.1 \%)$ & 0.880 \\
\hline Family history of CAD & $7(1.8 \%)$ & $5(1.7 \%)$ & $2(1.9 \%)$ & 0.919 \\
\hline Smoking & $118(29.6 \%)$ & $78(26.8 \%)$ & $40(37.4 \%)$ & $0.04^{*}$ \\
\hline \multicolumn{5}{|c|}{ Presentation } \\
\hline $\begin{array}{l}\text { Symptom to hospital arrival } \\
\text { time (minutes) }\end{array}$ & $240[120-400]$ & $240[120-420]$ & $240[120-360]$ & 0.242 \\
\hline $\begin{array}{l}\text { Door to balloon time } \\
\text { (minutes) }\end{array}$ & $100[100-150]$ & $100[100-150]$ & $100[100-150]$ & 0.966 \\
\hline Total ischemic time (minutes) & $367.5[250-545]$ & $380[250-580]$ & $340[240-510]$ & 0.330 \\
\hline $\begin{array}{l}\text { Systolic blood pressure } \\
(\mathrm{mmHg})\end{array}$ & $129.6 \pm 27.1$ & $130.5 \pm 28.1$ & $127.3 \pm 24.1$ & 0.292 \\
\hline $\begin{array}{l}\text { Diastolic blood pressure } \\
\text { (mmHg) }\end{array}$ & $80.5 \pm 16.5$ & $81 \pm 17.2$ & $79.3 \pm 14.4$ & 0.382 \\
\hline Heart rate (bpm) & $86.2 \pm 19.9$ & $86.7 \pm 20.5$ & $84.6 \pm 18.2$ & 0.335 \\
\hline Killip class III or IV & $49(12.3 \%)$ & $37(12.7 \%)$ & $12(11.2 \%)$ & 0.686 \\
\hline \multicolumn{5}{|c|}{$\mathrm{Rh}(\mathrm{D})$ grouping } \\
\hline Negative & $22(5.5 \%)$ & $17(5.8 \%)$ & $5(4.7 \%)$ & \multirow{2}{*}{0.651} \\
\hline Positive & $376(94.5 \%)$ & $274(94.2 \%)$ & $102(95.3 \%)$ & \\
\hline
\end{tabular}

$\mathrm{BMI}=$ body mass index $\mathrm{RV}=$ right ventricular, $\mathrm{CAD}=$ coronary artery diseases, ${ }^{*}$ statistically significant.

Angiographic findings and procedural characteristics are summarized in Table 2. Single vessel diseases were found to be significantly more prevalent among patients with blood group type $O$ with a distribution of $41.1 \%$ (44/107) vs. $29.6 \%$ (86/291); $p=0.029$ in type $O$ and non-O group respectively. Similarly, circumflex artery as the culprit was more common among type
O group with the distribution of $16.8 \%$ (18/107) vs. $9.6 \%$ (28/291); $p=0.046$ in type $O$ and non-O group respectively. Distribution of coronary dominance, pre-and post-procedure TIMI flow legion length and complexity, stenosis (\%), and left ventricular ejection fraction showed no significant association with blood group type $O$ and non-O.

Table 2: Angiographic findings and procedural characteristics of the patients stratified by the blood group type.

\begin{tabular}{|c|c|c|c|c|}
\hline \multirow{2}{*}{ Parameters } & \multirow{3}{*}{$\begin{array}{c}\text { Frequency } \\
\text { (n) (\%) } \\
\text { /Mean士SD }\end{array}$} & \multicolumn{2}{|c|}{ Blood Group } & \multirow[b]{2}{*}{$p$-Value } \\
\hline & & Non-O & 0 & \\
\hline$N=398$ & & $291(73.1 \%)$ & $107(26.9 \%)$ & - \\
\hline \multicolumn{5}{|c|}{ Coronary dominance } \\
\hline Right & $348(87.4 \%)$ & $251(86.3 \%)$ & $97(90.7 \%)$ & 0.240 \\
\hline Left & $9.8 \%(39)$ & $11.3 \%(33)$ & $5.6 \%(6)$ & 0.088 \\
\hline Co-dominance & $2.8 \%(11)$ & $2.4 \%(7)$ & $3.7 \%(4)$ & 0.472 \\
\hline \multicolumn{5}{|c|}{ Number of vessels involved } \\
\hline Normal & $3(0.8 \%)$ & $2(0.7 \%)$ & $1(0.9 \%)$ & 0.800 \\
\hline Single vessel disease & $130(32.7 \%)$ & $86(29.6 \%)$ & $44(41.1 \%)$ & $0.029^{*}$ \\
\hline Two vessel disease & $119(29.9 \%)$ & $93(32 \%)$ & $26(24.3 \%)$ & 0.139 \\
\hline Three vessel disease & $146(36.7 \%)$ & $110(37.8 \%)$ & $36(33.6 \%)$ & 0.446 \\
\hline
\end{tabular}




\begin{tabular}{|c|c|c|c|c|}
\hline \multicolumn{5}{|c|}{ Culprit artery } \\
\hline Normal/non-obstructive coronaries & $3(0.8 \%)$ & $2(0.7 \%)$ & $1(0.9 \%)$ & 0.800 \\
\hline Left anterior descending artery & $229(57.5 \%)$ & $167(57.4 \%)$ & $62(57.9 \%)$ & 0.921 \\
\hline Right coronary artery & $112(28.1 \%)$ & $88(30.2 \%)$ & $24(22.4 \%)$ & 0.124 \\
\hline Circumflex & $46(11.6 \%)$ & $28(9.6 \%)$ & $18(16.8 \%)$ & $0.046^{*}$ \\
\hline Left main & $1(0.3 \%)$ & $1(0.3 \%)$ & & 0.544 \\
\hline Diagonal & $2(0.5 \%)$ & $1(0.3 \%)$ & $1(0.9 \%)$ & 0.460 \\
\hline Obtuse marginal & $3(0.8 \%)$ & $2(0.7 \%)$ & $1(0.9 \%)$ & 0.800 \\
\hline Ramus & $2(0.5 \%)$ & $2(0.7 \%)$ & $0(0 \%)$ & 0.390 \\
\hline \multicolumn{5}{|c|}{ Pre-procedure TIMI flow } \\
\hline 0 & $217(54.5 \%)$ & $161(55.3 \%)$ & $56(52.3 \%)$ & 0.595 \\
\hline 1 & $28(7 \%)$ & $20(6.9 \%)$ & $8(7.5 \%)$ & 0.835 \\
\hline$\|$ & $93(23.4 \%)$ & $66(22.7 \%)$ & $27(25.2 \%)$ & 0.594 \\
\hline III & $60(15.1 \%)$ & $44(15.1 \%)$ & $16(15 \%)$ & 0.967 \\
\hline Stenosis (\%) & $94.25 \pm 12.98$ & $92.58 \pm 17.67$ & $95.1 \pm 11.06$ & 0.169 \\
\hline LVEF (\%) & $38.15 \pm 9.24$ & $37.72 \pm 9.04$ & $38.36 \pm 9.56$ & 0.534 \\
\hline Length of lesion (mm) & $21.83 \pm 9.04$ & $21.46 \pm 10.31$ & $21.42 \pm 8.52$ & 0.969 \\
\hline \multicolumn{5}{|c|}{ Lesion complexity } \\
\hline Low (Syntax: 0-22) & $295(74.1 \%)$ & $215(73.9 \%)$ & $80(74.8 \%)$ & 0.858 \\
\hline Intermediate (Syntax: 23-32) & $68(17.1 \%)$ & $55(18.9 \%)$ & $13(12.1 \%)$ & 0.113 \\
\hline High (Syntax:> 32) & $35(8.8 \%)$ & $21(7.2 \%)$ & $14(13.1 \%)$ & 0.067 \\
\hline \multicolumn{5}{|c|}{ Stenting } \\
\hline Stent placed & $346(86.9 \%)$ & $257(88.3 \%)$ & $89(83.2 \%)$ & 0.177 \\
\hline POBA & $39(9.8 \%)$ & $24(8.2 \%)$ & $15(14 \%)$ & 0.086 \\
\hline Unsuccessful & $13(3.3 \%)$ & $10(3.4 \%)$ & $3(2.8 \%)$ & 0.753 \\
\hline Collaterals & $19(4.8 \%)$ & $14(4.8 \%)$ & $5(4.7 \%)$ & 0.954 \\
\hline Severe calcification & $87(21.9 \%)$ & $66(22.7 \%)$ & $21(19.6 \%)$ & 0.513 \\
\hline Thrombus present & $333(83.7 \%)$ & $242(83.2 \%)$ & $91(85 \%)$ & 0.652 \\
\hline Bifurcation & $59(14.8 \%)$ & $46(15.8 \%)$ & $13(12.1 \%)$ & 0.363 \\
\hline Export use & $59(14.8 \%)$ & $42(14.4 \%)$ & $17(15.9 \%)$ & 0.717 \\
\hline \multicolumn{5}{|c|}{ Post-procedure TIMI flow } \\
\hline 0 & $12(3 \%)$ & $8(2.7 \%)$ & $4(3.7 \%)$ & 0.609 \\
\hline I & $6(1.5 \%)$ & $4(1.4 \%)$ & $2(1.9 \%)$ & 0.720 \\
\hline II & $29(7.3 \%)$ & $22(7.6 \%)$ & $7(6.5 \%)$ & 0.729 \\
\hline III & $351(88.2 \%)$ & $257(88.3 \%)$ & $94(87.9 \%)$ & 0.898 \\
\hline \multicolumn{5}{|c|}{ Post-procedure myocardial blush grade } \\
\hline 0 & $14(3.5 \%)$ & $9(3.1 \%)$ & $5(4.7 \%)$ & 0.448 \\
\hline 1 & $17(4.3 \%)$ & $14(4.8 \%)$ & $3(2.8 \%)$ & 0.380 \\
\hline 2 & $57(14.3 \%)$ & $47(16.2 \%)$ & $10(9.3 \%)$ & 0.086 \\
\hline 3 & $310(77.9 \%)$ & $221(75.9 \%)$ & $89(83.2 \%)$ & 0.123 \\
\hline
\end{tabular}

$\mathrm{TIMI}=$ thrombolysis in myocardial infarction, LVEF = left ventricular ejection fraction, POBA = plain old balloon angioplasty, *significant at $5 \%$

Post procedure complications and in-hospital outcomes are summarized in Table 3. Cumulative post procedure complications were noted in $27.1 \%$ (108) with requirement of mechanical ventilation (12.1\%), slow/no-reflow (11.8\%), and cardiogenic shock $(9.8 \%)$ as commonly observed complications.
In-hospital mortality rate was found to be $0.5 \%$ (2/398). Complication $(23.4 \%$ (25/107) vs. $28.5 \%$ (83/291); $p=0.554)$ and in-hospital mortality rate (0.9\% (1/107) vs. $0.3 \%$ (1/291); $p=0.642)$ was not statistically significant between blood group type $\bigcirc$ and non-O respectively. 
Table 3: Post-procedure complications and in-hospital outcomes of the patients stratified by the blood group type.

\begin{tabular}{|c|c|c|c|c|}
\hline \multirow{2}{*}{ Characteristics } & \multirow{2}{*}{$\begin{array}{c}\text { Frequency } \\
\text { (n) (\%) }\end{array}$} & \multicolumn{2}{|c|}{ Blood Group } & \multirow{2}{*}{ p-Value } \\
\hline & & Non -O & 0 & \\
\hline $\mathrm{N}=398$ & & $291(73.1 \%)$ & $107(26.9 \%)$ & - \\
\hline \multicolumn{5}{|c|}{ Clinical Complications/Outcomes } \\
\hline Overall complication & $108(27.1 \%)$ & $83(28.5 \%)$ & $25(23.4 \%)$ & 0.554 \\
\hline Mechanical ventilation & $48(12.1 \%)$ & $36(12.4 \%)$ & $12(11.2 \%)$ & 0.220 \\
\hline Hea rt block & $19(4.8 \%)$ & $17(5.8 \%)$ & $2(1.9 \%)$ & 0.079 \\
\hline Cardiogenic shock & $39(9.8 \%)$ & $29(10 \%)$ & $10(9.3 \%)$ & 0.429 \\
\hline Acute kidney injury & $3(0.8 \%)$ & $3(1 \%)$ & $0(0 \%)$ & 0.559 \\
\hline Sepsis & $1(0.3 \%)$ & $1(0.3 \%)$ & $0(0 \%)$ & 0.596 \\
\hline Acute stent thrombosis & $5(1.3 \%)$ & $4(1.4 \%)$ & $1(0.9 \%)$ & 0.889 \\
\hline Cardiac arrest & $3(0.8 \%)$ & $2(0.7 \%)$ & $1(0.9 \%)$ & 0.512 \\
\hline Arrhythmias & $8(2 \%)$ & $3(1 \%)$ & $5(4.7 \%)$ & 0.096 \\
\hline Pulmonary edema & $17(4.3 \%)$ & $15(5.2 \%)$ & $2(1.9 \%)$ & 0.252 \\
\hline Slow/no-reflow & $47(11.8 \%)$ & $35(12 \%)$ & $12(11.2 \%)$ & 0.813 \\
\hline Bleeding & $2(0.5 \%)$ & $2(0.7 \%)$ & $0(0 \%)$ & 0.154 \\
\hline Mortality & $2(0.5 \%)$ & $1(0.3 \%)$ & $1(0.9 \%)$ & 0.642 \\
\hline
\end{tabular}

\section{DISCUSSION}

This descriptive cross-sectional study was conducted to evaluate the association of the non-O and $O$ blood group distribution with the extent and severity of coronary artery lesions in AMI patients. No association was observed between the lesion complexity, as assessed by Syntax score, and blood group type $\bigcirc$ and non-O. Patients with blood group type $O$ had a lower burden of disease with single vessel diseases more common in this group as compared to the non-O group. Post-procedure complications and in-hospital mortality rates were not significantly different between the two groups. Among the significant differences, the smoking tendency was found to be significantly higher among the patients in blood group type $O$ with the frequency of $37.4 \%$ vs. $26.8 \%(p=0.04)$ as compared to the patients in a non-O blood group type. Such a relationship can partly be explained by the relatively higher age $(78.5 \%$ vs. $72.9 \%)$ and relatively higher male gender dominance $(58.07 \pm 11.88$ years vs. $56.82 \pm 10.59$ years) among the $\bigcirc$ blood group patients.

A study conducted by Celebi et al. evaluated the association between blood group types and the development of coronary collateral circulation in 212 patients with CAD and reported that poor collateral development is associated with non-O blood group type ${ }^{17}$. However, like our findings, a study by Rasmi et al. in an Iranian population also observed no association between the number of diseased vessels and $A B O$ distribution of blood group ${ }^{18}$. When $A B O$ distribution was studied for association with thrombus burden in 369 patients with ST-segment elevation myocardial infarction (STEMI) by Askin et al., no relationship with thrombus burden and $A B O$ blood type was noted ${ }^{19}$. But a study reported a positive relationship between spontaneous recanalization with blood group type $\mathrm{O}$ in patients with $\mathrm{AM}{ }^{20}$.
In contrary to our finding of no association between blood group type $\bigcirc$ and non-O and post-procedure complications and in-hospital mortality, a study by Cetin et al. on 1835 consecutive patients reported blood group type non-O as an indicator of the increased rate of in-hospital, short-term, long-term mortality, and adverse events in patients with STEMI after primary $\mathrm{PCl}^{21}$. However, this study also found no difference in lesion complexity (Gensini score) between the two groups. Similarly, Karabuva et al. also reported no association between the extent of coronary artery atherosclerosis and $\mathrm{ABO}$ blood groups ${ }^{22}$.

Among various other studies, a study of 3823 Chinese Han patients by Zhang et al. observed a strong association between non-O blood group and severe coronary atherosclerosis and higher inflammatory level with increased risk of cardiovascular event occurrence ${ }^{23}$. Similarly, blood group type $\mathrm{A}$ was reported as an independent risk factor of server coronary artery disease (based on Gensini score) ${ }^{24}$. In this study involvement of circumflex was observed to be more common among the patients with type $\bigcirc$ blood group as compared to the non-O type with the frequency of $16.8 \%$ vs. 9.6\%; $p=0.046$ respectively. These findings along with a higher proportion of the patients with single-vessel coronary artery disease among the type $\bigcirc$ blood group indicate lesser complexity and severity of atherosclerosis among these patients as compared to their non-O type counterparts. A similar observation of lesser complex associated disease was reported by the studies in past ${ }^{23,24}$. However, literature negates such association in a study conducted by Kaya et al. They reported 620 subjects having no significant results among any blood group type and coronary artery ectasia. Upon comparison of outcomes, no statistically 
significant difference was observed among the patients with type $O$ and non-O blood group, however, a relatively higher rate of complications was observed among patients in the non-O group with a frequency of $28.5 \%$ vs. $23.4 \%$ as compared to type $O$ groups. Relatively higher rates of complications among the non-O group were seen, including a higher rate of heart blocks $(5.8 \%$ vs. $1.9 \%)$ and pulmonary edema $(5.2 \%$ vs. $1.9 \%)$ as compared to the type $O$ groups respectively. However, arrhythmias were relatively more common among patients in type $O$ groups as compared to the non-O type with the frequency of $4.7 \%$ vs. $1.0 \%$ respectively ${ }^{25}$.

This study has certain limitations such as it was conducted in a single center with a relatively small sample size and due to the difference in the number of patients in blood group type $O$ and non-O, some of the differences may not be evident in statistical analysis. Cohort studies with a large sample size may be needed to validate the study findings.

\section{CONCLUSION}

Blood group type $O$ was found to be associated with single-vessel coronary artery diseases in patients with acute myocardial infarction undergoing primary percutaneous coronary intervention (PCI). However, no association of blood group type $O$ and non-O has been observed with the severity of coronary artery lesion and post-procedure complication and mortality.

\section{ACKNOWLEDGMENTS}

The authors wish to acknowledge the support of the staff members of the Clinical Research Department of the National Institute of Cardiovascular Diseases (NICVD) Karachi, Pakistan.

\section{CONFLICT OF INTEREST}

All authors have no conflict of interest to disclose.

\section{ETHICS APPROVAL}

This study was approved by the ethical review committee of the National Institute of Cardiovascular Diseases (NICVD), Karachi (ER-45/2020).

\section{PATIENT CONSENT}

Verbal informed consent was obtained from all the patients regarding their participation in the study and publication of data while maintaining confidentiality and anonymity.

\section{AUTHORS' CONTRIBUTION}

The idea conceived by JAS and GA study designed by JAS, GA, RK, KAK, and MK, study execution and data collection was done by JAS, GA, RK, KAK, AH, $D Q, M Z$, and FN manuscript drafted by JAS, GA, RK, $\mathrm{KAK}, \mathrm{AH}, \mathrm{FN}$, and MK, the manuscript was critically reviewed by $M Z$, JS, TS and MK, and the study was supervised by JAS. All authors have read and approved the manuscript.

\section{REFERENCES}

1. Nowbar AN, Gitto M, Howard JP, Francis DP, Al-Lamee R. Mortality from ischemic heart disease: Analysis of data from the World Health Organization and coronary artery disease risk factors From NCD Risk Factor Collaboration. Circ Cardiovasc Qual Outcomes. 2019;12(6):1-11. doi:10.1161/CIRCOUTC OMES. 118.005375

2. Mensah GA, Roth GA, Fuster V. The global burden of cardiovascular diseases and risk factors: 2020 and beyond. J Am Coll Cardiol. 2019;74(20):2529-2532. doi: 10.1016/j.jacc.2019.10.009

3. Pena MS, Rollins A. Environmental exposures and cardiovascular disease: a challenge for health and development in low-and middle-income countries. Cardiol Clin. 2017;35(1):71-86. doi: 10.1016/j.ccl.20 16.09.001

4. Gijsberts CM, den Ruijter HM, Asselbergs FW, Chan MY, de Kleijn DP, Hoefer IE. Biomarkers of coronary artery disease differ between Asians and Caucasians in the general population. Glob Heart. 2015;10(4):301-311. doi: 10.1016/j.gheart.2014.11.004

5. Steg PG, Ducroca G. Future of the prevention and treatment of coronary artery disease. Circ J. 2016;80(5):1067-1072. doi: 10.1253/circj.CJ-16-0266

6. Foreman KJ, Marquez N, Dolgert A, Fukutaki K, Fullman $N$, McGaughey $M$, et al. Forecasting life expectancy, years of life lost, and all-cause and cause-specific mortality for 250 causes of death: reference and alternative scenarios for 2016-40 for 195 countries and territories. Lancet. 2018;392(10159):2052-2090. doi:10.101 6/S0140-6736(18)31694-5

7. Wakefield MA, Loken B, Hornik RC.Use of mass media campaigns to change health behaviour. Lancet. 2010;376:1261-1271. doi: 10.1016/50140-6736(10)60809-4 8. The Lancet. The Astana Declaration: the future of primary health care? Lancet. 2018;392:1369. doi: 10.1016/S0140-6736(18)32478-4

9. Ozaki K, Tanaka T. Molecular genetics of coronary artery disease. J Hum Genet. 2016;61 (1):71-77. doi: 10.1038/jhg.2015.70

10. Li S, XU RX, Guo YL, Zhang Y, Zhu CG, Sun J, et al. $A B O$ blood group in relation to plasma lipids and proprotein convertase subtilisin/kexin type 9. Nutr Metab Cardiovasc Dis. 2015;25(4):411-417. doi: 10.1016/j.numecd.2014.10.015

11. Silbernagel G, Chapman MJ, Genser B, Kleber ME, Fauler $\mathrm{G}$, Scharnagl $\mathrm{H}$, et al. High intestinal cholesterol absorption is associated with cardiovascular disease and risk alleles in $A B C G 8$ and $A B O$ : evidence from the LURIC and YFS cohorts and from a meta-analysis. J Am Coll Cardiol. 2013;62(4):291-299. doi: 10.1016/j.jacc. 2013.01.100

12. Nafakhi H, Al-Nafakh HA, Al-Mosawi AA. ABO blood group differences relationship with coronary atherosclerotic markers. Artery Res. 2016;14:36-40. 
doi: 10.1016/j.artres.2016.03.001

13. Chen $\mathrm{Z}$, Yang $\mathrm{SH}, \mathrm{X} \cup \mathrm{H}$, Li JJ.ABO blood group system and the coronary artery disease: an updated systematic review and meta-analysis. Sci Rep. 2016;6(1):1-11. doi: 10.1038/srep23250

14. Reilly MP, Li M, He J, Ferguson JF, Stylianou IM, Mehta NN, et al. Identification of ADAMTS7 as a novel locus for coronary atherosclerosis and association of $A B O$ with myocardial infarction in the presence of coronary atherosclerosis: two genome-wide association studies. Lancet. $2011 ; 377(9763): 383-392$. doi: 10.1016/S01406736(10)61996-4

15. López-Mejías R, Genre F, García-Bermúdez M, Ubilla $B$, Castañeda S, Llorca J, et al. Lack of association between ABO, PPAP2B, ADAMST7, PIK3CG, and EDNRA and carotid intima-media thickness, carotid plaques, and cardiovascular disease in patients with rheumatoid arthritis. Mediators Inflamm. 2014;2014:1-7. doi: 10.1155/2014/756279

16. Amirzadegan A, Salarifar M, Sadeghian S, Davoodi G, Darabian C, Goodarzynejad H. Correlation between $\mathrm{ABO}$ blood groups, major risk factors, and coronary artery disease. Int J Cardiol. 2006;110(2):256-258. doi: 10.1016/j.jijcard.2005.06.058

17. Celebi S, Celebi OO, Berkalp B, Aydogdu S, Amasyali B. Blood group types $O$ and non-O are associated with coronary collateral circulation development. Clin Appl Thromb Hemost. 2020;26:1-6. doi: 10.1177/1076029619900544

18. Rasmi Y, Kheradmand F, Nemati M, Mollazadeh L, Seyyed-Mohammadzad MH, Shirpoor A, Khalaji N. Distribution of blood groups in patients with angiographically defined coronary artery disease in Iranian community. Sud J Med Sci. 2020; 15(3):215-222. doi: 10.18502/sjms.v15i3.7013

19. Askin L, Cetin M, Turkmen S. Absence of a correlation between the $\mathrm{ABO}$ blood group and thrombus burden in patients with ST-segment elevation myocardial infarction. Coron Artery Dis. 2018;29(2):145-150. doi: 10.1097/MCA.0000000000000564

20. Lin XL, Zhou BY, Li S, Li XL, LUo ZR, Li JJ. Correlation of $A B O$ blood groups with spontaneous recanalization in acute myocardial infarction. Scand Cardiovasc J. 2017;51 (4):217-220. doi:10.1080/14017431.2017.13120 13

21. Cetin MS, Cetin EH, Aras D, Topaloglu S, Temizhan A, Kisacik HL, et al. Non-O blood groups can be a prognostic marker of in-hospital and long-term major adverse cardiovascular events in patients with ST elevation myocardial infarction undergoing primary percutaneous coronary intervention. Thromb Res. 2015;136(3):599-605. doi: 10.1016/j.thromres.2015.07.031

22. Karabuva S, Carević V, Radić M, Fabijanić D. The association of $\mathrm{ABO}$ blood groups with extent of coronary atherosclerosis in Croatian patients suffering from chronic coronary artery disease. Biochem Med. 2013;23(3):351-359. doi: 10.11613/BM.2013.043

23. Zhang Y, Li S, Zhu CG, Guo YL, Wu NQ, Xu RX, et al. Risk factors, coronary severity, outcome and ABO blood group: a large Chinese Han Cohort Study. Medicine. 2015;94(43):1-8. doi: 10.1097/MD. 0000000000001708

24. Hong XL, Li Y, Fu GS, Wu H, Wang Y, Gu CX, et al. Association of $A B O$ blood groups with the severity of coronary artery disease: a cross-sectional study. J Geriatr Cardiol. 2019;16(9):701-705. doi: 10.11909/j. issn.1671-5411.2019.09.005

25. Kaya H.Is there any relationship between abo blood groups and coronary ectasia? Int J Blood Res Disord. 2019;6(1):1-4. doi: 10.23937/2469-5696/1410043. 